\title{
Análise Psicossocial do Assentamento e seu Entorno
}

\author{
Francisco José Batista de Albuquerque ${ }^{12}$ \\ Tatiana Cristina Vasconcelos \\ Jorge Artur Peçanha de Miranda Coelho \\ Universidade Federal da Paraíba
}

\begin{abstract}
Resumo
Considerando que o processo de assentamento se completa quando há uma efetiva integração entre assentados e comunidade, objetivou-se comparar as crenças e expectativas existentes entre os pequenos produtores assentados e seus vizinhos moradores de pequenas parcelas adquiridas através de herança ou compra. Cinqüenta e dois assentados e 53 pequenos proprietários participaram de grupos focais e entrevistas individuais sobre a história de sua comunidade, suas expectativas etc. Os resultados mostraram que os assentados descrevem seus vizinhos como desorganizados e acomodados, já os pequenos agricultores percebem os assentados como invasores de terras e beneficiados pelo governo. Ambos descrevem o contato social com o exogrupo como negativo devido aos preconceitos existentes de lado a lado. Conclui-se que embora o assentamento tenha por finalidade integrar seus membros à comunidade, esse objetivo não foi alcançado, implicando a necessidade de uma política integradora e que trate os agricultores de forma homogênea, independente da maneira como lograram a terra.

Palavras-chave: Assentamentos; identidade social; preconceito.
\end{abstract}

Psychossocial Analysis of the Settling and its Surroundings

\begin{abstract}
We hereby aim at comparing the beliefs and the existing expectations between small-settled growers and their neighbours, who either purchased or inherited small-properties, by taking into account that the settling process only gets completed when there is an effective integration between settlers and the community. Five-two settlers and 53 small-property owners took part in focus groups and individual interviews were carried out concerning the history of their community, expectations and so on. The results showed that settlers describes their neighbours as non-fighting-for-life disorganized people, while small-property owners see settlers as government-benefited land invaders. Both of them describe the social contact with the exogenous group as negative due to the existing prejudices on both sides. We are there led to conclude that although settling aims at integrating its members with the community, such target is not attained. This points to the need for an integrating policy- so as to contemplate a homogeneous form of treatment for growers- no matter how they managed to own the land.

Keywords: Settling; social identity; prejudice.
\end{abstract}

O processo de reforma agrária no Brasil é considerado como bastante complexo e difícil de entender e de superar. Sua análise tem como foco, principalmente, os fatores econômicos e sócio-demográficos, observando-se uma escassez de estudos que enfatizem os fatores psicológicos ou psicossociais dos diversos grupos diretamente envolvidos nesse processo, como os técnicos, os assentados e seus vizinhos. Levando-se em consideração que o processo de assentamento se completa quando há uma integração efetiva entre os assentados e os pequenos produtores rurais do seu entorno, buscou-se comparar as crenças e expectativas existentes entre os pequenos produtores, oriundos dos projetos de assentamento da reforma agrária, e seus vizinhos,

\footnotetext{
${ }^{1}$ Agradecimentos: Ao Conselho Nacional de Desenvolvimento Tecnológico e Científico-CNPq pelo financiamento cedido e ao professor $\mathrm{Dr}^{\circ}$ Jorge Raymundo da Silva pelas valiosas sugestões e correções que foram fundamentais para realização desse estudo.

${ }^{2}$ Endereço para correspondência: Rua Maria Jaci da Costa, 201, 1101, Bl B, Bessa, 58036 110, João Pessoa, PB.E-mail:frajoba@uol.com.br
}

moradores de pequenas parcelas adquiridas através de herança ou de compra.

Entre os assentados e os pequenos agricultores que logram a terra através de compra ou herança, existem grandes diferenças psicossociais, embora convivam no mesmo espaço territorial e padeçam das mesmas misérias. Por sua origem, uns são bóias-frias, sem terras, enquanto outros são ou filhos de pequenos e médios proprietários, ou trabalhadores que de alguma forma conseguiram poupar o suficiente para individualmente comprar sua própria terra. Essas bases originárias formam valores diferentes entre esses grupos, no que se refere à terra, sua posse e exploração. Além disso, os assentados, pelo seu nível de organização e apoio político e institucional, recebem tratamento diferenciado em relação à assistência técnica e creditícia, o que pode acarretar diferenciações psicossociais.

A psicologia social pode contribuir de forma considerável para a compreensão desses aspectos psicossociais. Entretanto, tem se mantido afastada de todo o processo de transformação ocorrido no mundo rural, dedicando-se quase exclusivamente 
à análise dos fenômenos urbanos e dos seus habitantes (maiores detalhes, ver Albuquerque, 1994, 1996; Clemente \& Albuquerque, 1998; Clemente, Albuquerque \& Reyes, 1993). Não obstante, pode-se constatar que cada vez mais se faz necessária a presença da psicologia social para explicar e, quando for o caso, intervir no processo de mudança que está ocorrendo na realidade brasileira (Albuquerque, 2001).

A reivindicação do acesso à terra, pelo Movimento dos Trabalhadores Rurais Sem Terra (MST) e por outras organizações, levou à implantação de numerosos assentamentos, ainda que com uma atenção limitada no que diz respeito às demandas (Jorge \& Bergamasco, 1998). A palavra assentamento, enquanto substantivo, refere-se ao conjunto de famílias de trabalhadores rurais, vivendo e produzindo num determinado imóvel rural, desapropriado ou adquirido através do governo federal e/ou estadual, e com o fim de cumprir as disposições constitucionais e legais relativas à reforma agrária. Carvalho (1998) acrescenta a outros entendimentos que "a expressão assentamento é utilizada para identificar não apenas uma área de terra no âmbito dos processos de reforma agrária destinada à produção agropecuária e/ou extrativista, mas também um agregado heterogêneo de grupos sociais constituídos por famílias de trabalhadores rurais" (p. 7).

As pessoas e famílias assentadas passam por um extenso processo de construção de sua infra-estrutura social e econômica, depois de implantadas. Além disso, no assentamento, enquanto espaço social em reconstrução, as pessoas, algumas estranhas entre si, passam a interagir com os membros do próprio assentamento e com os moradores circunvizinhos. Como conseqüência dessas novas interações, podem surgir identificações ou conflitos, tanto intra como intergrupais. Neste contexto, algumas questões clássicas da psicologia social, referentes aos grupos e à formação da identidade social, podem ser aqui apresentadas. Algumas delas são: quando um agregado de indivíduos passa a ser considerado um grupo social? O que faz com que um grupo permaneça unido ou se desintegre?

Inicialmente, para que um coletivo se transforme em grupo, Bar-Tal (1996) afirma que existem três condições necessárias: 1) que os componentes desse coletivo se definam como membros do grupo; 2) que compartilhem das mesmas crenças grupais; e 3) que exista algum grau de atividade coordenada entre seus membros. Outros fatores relevantes na definição de grupo é que seus membros tenham objetivos comuns, normas sociais estabelecidas e respeitadas, bem como uma ideologia compartilhada (Krech, Crutchfield \& Ballachie, 1962).

Na situação de assentamento, as pessoas e famílias podem ser provenientes ou não de uma mesma região, e, na maioria das vezes, não estabeleceram contato social anterior. Depois de definidos os objetivos comuns de aceder a terra, estabelecidas as normas de funcionamento do grupo e surgido o caráter continuamente construído de interação voluntária, os assentados, que antes constituíam apenas um agregado, passam a ser considerados como um grupo, no qual os membros estão conscientes de que têm algo em comum e que possuem uma nova identidade social. A partir de então, como aponta Lewin (1948), o grupo passa a ser a referência sobre a qual se apóia o indivíduo, bem como o instrumento para satisfazer suas necessidades físicas e sociais. Essa relação intragrupo que se inaugura, caracterizada pelo fortalecimento das interações no assentamento, não é necessariamente estendida aos demais grupos constituídos. Um exemplo disso acontece com os pequenos agricultores que habitam as circunvizinhanças do assentamento, formando um grupo que anteriormente já se encontrava instalado territorialmente e com metas formuladas. Nesses casos, podem ocorrer conflitos intergrupais. Dessa forma, entender o que sucede entre esses grupos sociais é de suma importância, tanto para a psicologia social como para o bemestar de seus membros, sendo importante que novas relações se estabeleçam entre eles para que possa existir um conjunto com relações homogêneas.

$\mathrm{Na}$ análise do comportamento intergrupal e do surgimento das normas de grupo, os estudos de Sherif (1984) surgem como uma das perspectivas mais importantes. Segundo Casal (1989), esses estudos se caracterizam basicamente pela criação experimental de determinadas relações funcionais entre as metas de grupos que interagem, sejam elas de competição, de cooperação ou de independência, para se tentar constatar seus efeitos na conduta intergrupal. Como acrescenta Myers (2000), Sherif observou que, quando são estabelecidas metas alcançáveis apenas para um grupo, ocorrem conflitos, podendo-se chegar a preconceitos e discriminações grupais.

Para se proceder a uma análise dos processos intergrupais entre os assentados e seus vizinhos, não se pode negar a relação funcional entre estes grupos, mas também se torna necessário considerar outro aspecto importante, que é a formação da identidade social.

\section{Identidade Social}

O processo psicológico de construção da identidade social tem sido estudado por Tajfel (1978, 1982; citado em Bar-tal, 1996). Desses estudos, resulta o papel ativo que cada indivíduo desempenha na construção de sua identidade, sendo as crenças e expectativas fatores importantes na formação das normas sociais (Turner, 1994). Estudar a noção de identidade social é, provavelmente, uma das tarefas mais complexas na psicologia social, como afirma Montero (1996), devido à contradição entre permanência e mudança, pois, ao se falar de identidade social, refere-se a um processo em contínua construção. Apesar dessa complexidade, Bar-Tal (1996) assinala que a Teoria da Identidade Social de Tajfel, elaborada em 1978, é uma importante teoria da Psicologia, que 
ajuda a compreender os processos intra e intergrupais, e oferece uma visão única de um amplo conjunto de condutas individuais e sociais. Nesse sentido, esta teoria pode contribuir, de maneira considerável, para a análise psicossocial dos fenômenos ocorridos nos assentamentos e em seu entorno. Isto acontece porque, em função das suas características, os assentamentos propiciam um ambiente no qual a construção de uma identidade social encontra o seu solo mais fértil.

A Teoria da Identidade Social (TIS) aponta que os atores sociais adotam uma identidade pessoal, e que também constróem uma identidade social que reflete sua pertença aos vários grupos aos quais crêem pertencer. A Identidade Social é definida por Tajfel como sendo a parte do autoconceito de um indivíduo, derivado de seu conhecimento de sua pertença a um grupo ou grupos sociais, e unido ao valor e significado emocional desta pertença. As identidades sociais em forma de categorias, como nacionalidade, religião, gênero, profissão, entre outras, constituem partes importantes na formação do autoconceito, pois é através delas que as pessoas percebem a si mesmas e ao mundo que as rodeia (Bar-Tal, 1996).

Especificamente, em um determinado assentamento, as interações sociais que as pessoas estabelecem entre si, assim como com as diversas pessoas e famílias que vivem fora do assentamento, possibilitam-lhes estabelecer uma multiplicidade de tipos de categorias sociais. Muitas dessas pessoas e famílias acabam por se identificar entre si em função das afinidades que supõem existir entre elas (Carvalho, 1999). A identidade social como um grupo constitui-se a partir das vivências e percepções compartilhadas por este grupo no espaço e no tempo, sendo um produto históricosocial percebido subjetivamente por cada pessoa e alcançada na interação. É através desta identidade que o ator social orienta suas condutas, organiza seus projetos, constrói sua história e busca resolver suas contradições em interações constantes com outros atores sociais. Sendo uma construção social, deve-se supor que esta identidade se define por oposição a outros atores, estando pautada não somente em função do endogrupo, mas também do exogrupo (Montero, 1996).

Com base na diferenciação grupal, Turner (1981) afirma que o fato de definir um grupo em relação a outro, mesmo que de maneira trivial, produz favoritismo endogrupal. Myers (2000) apresenta vários estudos que demonstram empiricamente esta afirmação. Por exemplo, em um experimento de laboratório foi observado que apenas partilhar a crença fictícia de uma mesma data de aniversário com alguém criou vínculo suficiente para produzir uma cooperação mais acentuada entre os supostos aniversariantes. Do mesmo modo, Bilig e Tajfel (1973) destacam que apenas formar grupos, sem qualquer base lógica, como, por exemplo, intitular dois grupos como X e Y, a partir do cara ou coroa, produz os mesmos resultados. Desses estudos, concluise que, ao categorizar dois grupos de maneira mutuamente excludente, para realizarem uma tarefa em que há distribuição de recursos limitados, os indivíduos avaliam todos os envolvidos na tarefa e acabam favorecendo um membro de seu próprio grupo frente a um do exogrupo.

Considerando esse aspecto, a TIS parte da premissa básica de que todos têm uma necessidade de alcançar uma identidade individual positiva e que o status que têm os grupos de pertença ajuda a conseguí-la. Com este intuito, o indivíduo permanece num contínuo processo de comparação grupal, avaliando o endogrupo de maneira que supere sempre o exogrupo (Drigotas, Insko \& Schopler, 1996). É neste sentido que Turner (1994) aponta a tendência dos indivíduos de avaliarem o próprio grupo em termos positivos, para avaliarem a si mesmos positivamente.

Para a melhor compreensão do funcionamento e da organização de um grupo, é de fundamental importância o entendimento de fatores componentes da sua estrutura, como por exemplo, a liderança e a coesão. Num grupo o surgimento de um líder se dá a partir da posição formal ou informal dos indivíduos na sua estrutura. No caso posição informal, a liderança surge através das interações intragrupais, nas quais os membros percebem um determinado indivíduo como sendo aquele que mais contribui para a realização dos objetivos do grupo. Com relação à coesão, é um fator determinante para o sucesso de qualquer atividade exercida pelos indivíduos integrantes de um grupo, de forma que um grupo coeso tem mais chances de manter-se unido e com uma vasta história de êxito. Nesse sentido, um grupo é diferenciado de outros devido à coesão, pois quanto maior a coesão maior, será a comunicação existente entre seus membros, a produtividade e a satisfação, entre outros aspectos (Jesuíno, 1996).

Reportando ao assentamento, observa-se que, durante os meses ou anos em que ficam acampadas em situações precárias, as dezenas ou centenas de famílias do futuro assentamento identificam-se entre si, em função de um objetivo comum, que é a posse da terra. Para ser alcançado esse objetivo, faz-se necessária a colaboração de todos, posto que, de forma individual, nenhum deles consegue ter acesso ao seu próprio pedaço de chão. Neste momento, o nível de coesão grupal é bastante elevado porque todos necessitam de todos para conseguir o objetivo comum, que redundará, em última análise, na satisfação de um objetivo individual. Entretanto, passado algum tempo após conseguirem a posse da terra, este nível de coesão tende a enfraquecer, pois os objetivos a serem alcançados dependem mais de metas pessoais ou familiares que de todo o grupo (Albuquerque, 2000; Bonavigo, 1998; Carvalho, 1998). Mesmo com esta significativa diminuição da coesão grupal, os assentados têm claro que no momento de alcançarem outros objetivos do grupo, como, por exemplo, a infra-estrutura para o assentamento, os membros precisam voltar a se unir, aumentando novamente o nível de coesão grupal. 
A coesão existente entre os membros do assentamento não implica que haja uma maior aproximação ou entendimento com os outros pequenos agricultores que, embora vizinhos, não participaram do movimento para a consecução do assentamento (Albuquerque, 2000). Os agricultores circunvizinhos sentem-se como uma comunidade à parte do assentamento, tanto por sua origem, quanto pelos benefícios que aos outros são disponibilizados, como crédito para construção da moradia, custeio e investimentos a baixo custo e com carência, assistência técnica, além da organização e apoio políticos presentes. Os assentados e as familias circunvizinhas apresentam grande heterogeneidade de histórias de trabalho e amplo senso de vida, em decorrência não somente das diferentes relações sociais de produção e de propriedade em que estavam inseridos, mas também pelos contextos histórico-sociais em que se encontravam, como pessoas e como famílias. Há diferenciações pelo grau de organização corporativa que tenham conseguido alcançar em determinadas conjunturas, no âmbito das suas lutas reivindicatórias ou pela intensidade dos conflitos sociais que tenham vivenciado. Ademais, como afirma Carvalho (1999), existe uma diferenciação na memória de vida, sendo importante destacar que cada grupo social tende a aviltar o outro. Ademais, quanto mais importante for a identidade social e mais forte a ligação com o endogrupo, mais se reage com preconceitos a outros grupos, o que dificulta e impossibilita a prontidão para manter contato social com o exogrupo (Martinez, 1996).

Como mencionado anteriormente, o assentamento terá obtido seu objetivo, na medida em que deixe de se diferenciar da comunidade que o cerca, passando a integrá-la, produzindo e participando do seu dia-a-dia. Contudo, este objetivo aparentemente óbvio não é de fácil assimilação, nem pelos técnicos dos órgãos governamentais encarregados da sua implementação, nem pelos próprios assentados, nem, tampouco, pelos pequenos proprietários não-assentados. As razões para isto prendem-se tanto a fatores de ordem institucional, quanto a fatores psicológicos que dizem respeito à formação da identidade social dos diversos atores. Notase uma lacuna na atuação desses organismos, que pode ser estimulada a partir de algumas contribuições do ponto de vista da psicologia social que facilitem esta integração. Um primeiro passo é o conhecimento das crenças e expectativas dos diversos atores envolvidos no processo. Em seguida, pode-se tentar estabelecer uma metodologia de ação coerente com os objetivos de integração, tão necessários para a afirmação de todo o processo de reforma agrária no Brasil (Albuquerque, 2000).

Diante do exposto, objetivou-se, especificamente, nesta pesquisa: 1) analisar as crenças e as expectativas dos assentados e dos pequenos produtores vizinhos sobre o seu futuro e o de sua comunidade; 2) analisar qual a avaliação dos produtores vizinhos sobre a organização do assentamento; e 3) conhecer acerca da relação intergrupal entre assentados e pequenos produtores.

\section{Método}

\section{Hipóteses}

Considerando os objetivos explicitados e a literatura existente acerca dessa problemática, foram elaboradas as seguintes hipóteses: 1) os assentados apresentarão expectativas relacionadas à sua comunidade mais positivamente que os produtores vizinhos; 2 ) os assentados irão perceber-se como mais bem organizados politicamente do que os pequenos produtores vizinhos, sendo estes considerados acomodados; 3) os pequenos produtores perceberão os assentados como invasores de terras e privilegiados pelo governo; e 4) as percepções encontradas nestas três hipóteses afetarão negativamente os contatos sociais intra e inter-grupais

\section{Participantes}

A amostra foi constituída por 105 participantes, distribuídos entre assentados $(n=52)$ do assentamento Dona Helena, situado no município de Espírito Santo - Paraíba, e agricultores circunvizinhos a este assentamento $(n=53)$, sendo divididos de acordo com o sexo e a faixa etária: jovens, adultos e idosos (Tabela 1).

Tabela 1

Distribuição dos Grupos que Compõem a Amostra em Sexo e Faixa Etária

\begin{tabular}{lccccc}
\hline & \multicolumn{2}{c}{ Assentamento } & \multicolumn{3}{c}{ Comunidade vizinha } \\
\hline Jovens & masculino & feminino & masculino & feminino & Total \\
Adultos & 08 & 09 & 10 & 08 & 35 \\
Idosos & 09 & 10 & 11 & 10 & 40 \\
& 09 & 07 & 08 & 06 & 30 \\
\hline Total & 26 & 26 & 29 & 24 & 105 \\
\hline
\end{tabular}




\section{Instrumento}

O instrumento utilizado foi um roteiro de entrevista semidirigida, com o objetivo de estimular a verbalização dos participantes sobre os seguintes temas: história da comunidade, relacionamentos e conflitos com as comunidades vizinhas, expectativas sobre o futuro da comunidade e expectativas sobre o futuro profissional.

\section{Procedimento e Análise dos Dados}

$\mathrm{O}$ assentamento Dona Helena foi escolhido porque em seu entorno existe uma elevada densidade de pequenos agricultores rurais. Inicialmente, procederam-se visitas prévias ao assentamento, a fim de esclarecer aos líderes comunitários os objetivos da pesquisa, sendo solicitada a permissão para que o trabalho fosse realizado com os seus moradores. Após a autorização, foram marcados, com os moradores, os locais de reuniões para a realização da coleta de dados.

A coleta de dados foi realizada através da Técnica de Grupo Focal e de entrevistas individuais. A necessidade da utilização de entrevistas se deu porque, em alguns casos, os participantes tiveram que ser entrevistados individualmente, pois as características da comunidade, com casas a quilômetros de distância, impossibilitaram a realização de grupos focais. Todavia, em ambas as técnicas, a fim de que fossem evitados viéses, foi utilizado um procedimento padrão, no qual os pesquisadores foram responsáveis pela amostra de homens, enquanto as pesquisadoras ficaram responsáveis pelas mulheres.

O grupo focal é uma técnica que visa, tal como a entrevista, possibilitar que os indivíduos expressem suas opiniões, crenças e atitudes. Além disso, por ser constituído por um grupo de pessoas, possibilita a discussão sobre o tema que for iniciado pelo facilitador e uma maior visão da dinâmica intragrupal dos participantes. Para a sua realização, recomenda-se que seja constituído por um número de 10 a 12 pessoas, levando-se em conta que quanto menor o grupo maior é a participação das pessoas. Esta técnica não busca consensos, mas discussões e cabe ao facilitador ter bem definidos os seus interesses e objetivos de investigação, para que a discussão possa gerar conhecimento. Cabe mencionar que o papel do facilitador é fundamentalmente diretivo (para maiores detalhes, ver Krueger, 1996).

Os grupos focais foram realizados em lugares sugeridos pelos próprios moradores, como o terraço ou a sala de suas residências. Seguindo o procedimento da técnica, um pesquisador assumiu o papel de facilitador e iniciou informando que não existiam respostas certas ou erradas e que os dados seriam tratados com sigilo. Em seguida, introduziu uma conversa relacionada ao ambiente rural, para depois realizar as perguntas. Outro pesquisador assumiu o papel de observador, realizando as devidas anotações e interferindo o mínimo possível. Por fim, as respostas foram gravadas com a permissão dos participantes, e categorizadas através da Técnica de Análise de Conteúdo.

\section{Resultados e Discussão}

Com o intuito de facilitar a sua compreensão, os resultados foram discutidos na seqüência em que estão apresentados nas diversas tabelas. Inicialmente, objetivou-se analisar as diferenças encontradas entre assentados e moradores vizinhos ao assentamento, no que se refere às expectativas em relação ao seu futuro e ao futuro de sua comunidade. Os resultados são apresentados na Tabela 2.

Com relação às Expectativas Positivas que assentados e agricultores vizinhos ao assentamento possuem, foram abordados sete aspectos: Trabalho/Continuidade, Posse da Terra, Educação, Água/ energia, União, Saúde e Êxodo. Quanto ao aspecto Trabalho/Continuidade, os assentados apresentaram uma

Tabela 2

Expectativas em Relação ao Futuro

\begin{tabular}{llcc}
\hline \multirow{2}{*}{ Futuro da comunidade } & & \multicolumn{2}{c}{ Freqüências } \\
& & Assentamento & Comunidade vizinha \\
\hline Expectativa positiva & Trabalho/continuidade & 26 & - \\
& Posse de terra & - & 12 \\
& Educação & 9 & 5 \\
& Água/energia & 6 & - \\
& União & 6 & - \\
& Saúde & 5 & 13 \\
Expectativa negativa & Sem objetivo de vida & - & 5 \\
& Exxodo & 1 & \\
\hline
\end{tabular}


freqüência de 26 respostas. Esses dados revelam a importância que os assentados concedem a esse fator, no que concerne à continuidade em permanecerem morando na terra. Percebe-se também uma preocupação em gerar empregos, tanto para os filhos como para pessoas externas ao assentamento, sendo este um objetivo da maioria dos assentados. Pode-se observar que, na comunidade vizinha, este aspecto não foi contemplado. Por outro lado, com relação ao aspecto Posse da Terra, ocorre o inverso. Isto se dá devido ao fato de que, entre os assentados, a posse da terra já foi alcançada legalmente, enquanto os produtores circunvizinhos ao assentamento, embora tenham sua terra para plantar, ainda se preocupam com a legalidade e com a possibilidade de terem direito a uma maior extensão de terra.

$\mathrm{O}$ aspecto Educação, ou seja, ter assistência educacional de forma contínua na comunidade, foi uma das expectativas positivas apresentadas tanto pelos assentados quanto pelos moradores circunvizinhos ao assentamento, com nove respostas no primeiro grupo e cinco no segundo grupo. Este fato se deve à percepção de que a educação servirá para possibilitar aos jovens pequenos agricultores, independentemente do grupo de pertença, uma melhor qualidade de vida no futuro. Entretanto, cabe destacar que, para os assentados, a educação é vista como algo que contribui para que seus filhos trabalhem de maneira mais eficaz na própria terra. Já para os produtores vizinhos, a educação contribui como possibilidade de que os jovens trabalhem na cidade, fora da terra em que residem. Dessa maneira, percebem a educação como meio de elevação social e ascensão ao mercado de trabalho, o que, para eles, se daria na cidade e não na terra.

Outro aspecto igualmente ressaltado como expectativa positiva para os dois grupos, foi ter Água/Energia na sua comunidade: seis respostas foram apresentadas pelos assentados e cinco por seus vizinhos. Apesar das diferenças em relação à posse da terra, observou-se que os pequenos produtores têm claro que, em suas comunidades, a falta de saneamento básico é algo que dificulta uma boa moradia.

A união foi representada, no grupo de assentados, como o desejo de que, entre os membros do assentamento, exista mais união para que possam alcançar suas metas. Os assentados demonstraram sua insatisfação frente à união do grupo, que, diziam eles, era maior antes da posse da terra. Isto corrobora o que descrevem Bonavigo (1998) e Carvalho (1998). Também Sherif (1984) verificou em seus estudos experimentais que, quando existe um objetivo comum a ser alcançado, a coesão, a comunicação e a cooperação grupal são muito elevadas. Não obstante, depois de alcançado o objetivo comum, esses fatores tendem a enfraquecer, prevalecendo os objetivos individuais sobre os coletivos. Nessa ocasião, cada subgrupo, seja ele familiar, religioso, ou de outro tipo, realiza suas tarefas independentemente do grupo em geral. Em função disso, diminui o número de reuniões para as tomadas de decisões: se antes da posse da terra elas eram quase diárias, agora passam a ser, por exemplo, quinzenais ou mensais. Uma vez que estas reuniões constituem um dos fatores que favorecem a manutenção da identidade grupal, esta identidade tenderá a se enfraquecer. Neste sentido, estes dados demonstram a clareza, por parte dos assentados, de que a "união" é algo fundamental para que logrem seus objetivos. Por sua vez, chamam a atenção para o fato de que os não-assentados não consideram este aspecto como sendo um dos fatores que permeiam suas expectativas com relação ao futuro.

No que se refere à Saúde, encontra-se fortemente atrelada à união endogrupal e ao alcance de metas. A freqüência de cinco respostas revela que os assentados esperam ter condições físicas e mentais para lutar a fim de conseguirem lograr seus objetivos.

Um aspecto igualmente importante refere-se ao $\hat{E} x o d o$, que foi descrito como a necessidade de migrar para a cidade em busca de melhores empregos e condições de vida, com uma resposta para os assentados e cinco respostas para os moradores vizinhos ao assentamento.

Com relação às Expectativas Negativas acerca do futuro, encontrou-se, apenas entre os agricultores vizinhos, o aspecto Sem Objetivo de Vida, com uma freqüência de 13 respostas. Este aspecto contempla o sentimento de desesperança existente entre os moradores vizinhos, que afirmam não acreditar em melhoras na sua condição de vida, e dizem ser melhor não terem expectativas.

Diante do exposto, dois resultados aparecem como mais salientes: o que diz respeito à expectativa dos assentados de continuarem trabalhando em sua comunidade, e a falta de expectativa ou objetivo dos pequenos produtores vizinhos ao assentamento. Estes e outros resultados corroboram a hipótese de que, apesar das dificuldades, os assentados apresentam mais expectativas positivas do que negativas em relação a sua comunidade.

Objetivando verificar como os pequenos produtores nãoassentados avaliam a organização do assentamento, foram encontrados três tipos de avaliações. A primeira delas destacou positivamente a organização grupal do assentamento, por possibilitar maior Coesão e Liderança. Observou-se, também, uma avaliação negativa devido à Desorganização existente no assentamento. Por fim, foi encontrada uma acentuada freqüência de respostas de pessoas que não souberam avaliar a organização do assentamento (Tabela 3). 
Tabela 3

Avaliação dos Pequenos Agricultores Vižinhos sobre a Organização do Assentamento

\begin{tabular}{llc}
\hline Organização do assentamento & Comunidade vizinha \\
\hline Avaliação positiva & União/luta & 13 \\
& Liderança & 8 \\
Avaliação negativa & Desorganização & 1 \\
Não sabem & & 6 \\
\hline
\end{tabular}

Os participantes realizaram uma Avaliação Positiva com relação à organização do assentamento, ressaltando dois fatores: 1) consideram os assentados como um grupo Coeso e que Luta para conseguir seus objetivos, com um total de 13 respostas; e 2) devido à existência de um Líder entre os assentados, com um total de oito respostas. Este resultado aponta que, da mesma forma que os assentados, os pequenos proprietários percebem a importância da coesão endogrupal para a dinâmica social da comunidade, ressaltando que estes aspectos faltam à sua comunidade. De modo geral, todos os participantes acreditam que a coesão e a presença de um ou vários líderes podem contribuir para que exista um direcionamento na tomada de decisões grupais, pois os líderes possibilitam o processo de desenvolvimento da comunidade. Esta crença está de acordo com a afirmação de Jesuíno (1996) de que a coesão contribui positivamente para o grupo.

No que diz respeito à avaliação negativa da organização do assentamento, encontrou-se apenas uma resposta dada pelos pequenos proprietários, e que considera o assentamento como desorganizado, mesmo quando existe um líder. Muitos desses participantes não souberam avaliar a organização do assentamento, afirmando que não conhecem nada a respeito, por nunca terem ido até um assentamento. Daí, o que se pode concluiré que os pequenos proprietários têm pouca ou nenhuma relação com os moradores do assentamento.

A fim de conhecer a dinâmica social existente entre os grupos de assentados e pequenos produtores, no que se refere aos aspectos psicossociais do preconceito entre os dois grupos, solicitou-se que relatassem como percebem ou avaliam o exogrupo.

As avaliações foram baseadas em dois parâmetros: um positivo e outro negativo. Com relação à avaliação positiva do exogrupo, encontraram-se dois aspectos, um apresentado pelos assentados e o outro pelos vizinhos. O primeiro aspecto, categorizado como Contato Anterior, com onze relatos, diz respeito à avaliação positiva que nove assentados fizeram dos seus vizinhos. Essa avaliação positiva deveu-se ao fato dos assentados já terem mantido algum tipo de contato, considerado agradável, com os pequenos proprietários, em diferentes situações e por motivos variados, por exemplo, por serem colegas, por conversarem e por se encontrarem na feira livre. O segundo aspecto, denominado de Beneficiados, com sete relatos, refere-se à avaliação positiva dos pequenos proprietários em relação aos assentados, devido ao fato destes possuírem apoio do Estado para plantar e colher, o que significa algo que eles não recebem, mas desejam.

Sobre a avaliação negativa do exogrupo, apresentam-se dois aspectos na avaliação feita pelos assentados acerca dos pequenos proprietários. No primeiro aspecto, denominado de Acomodados/Desorganizados, os assentados consideram que falta iniciativa, por parte de seus vizinhos, para lutarem em busca da concretização dos seus ideais, devido à falta de liderança, associação e coesão grupal, com uma freqüência de 28 respostas. O segundo aspecto, que obteve três respostas, foi categorizado como Não-Proprietários, devido ao fato de que nem sempre os agricultores circunvizinhos são os proprietários da terra que utilizam para o plantio. Com base nestes resultados, confirmou-se a hipótese de que os assentados percebem a si mesmos como mais organizados politicamente do que os pequenos produtores vizinhos, e percebem seus vizinhos como individualistas, desorganizados e sem coragem para lutar pelos seus direitos em busca de mais terras para trabalhar.

Em contrapartida, os pequenos agricultores avaliam negativamente os assentados, pois os consideram como Invasores, pelo fato de ocuparem terras de terceiros, com uma freqüência de 16 respostas e como Violentos, por usarem da força para a aquisição da terra, com um total de quatro respostas. Estas respostas corroboram a hipótese de que os pequenos proprietários percebem os assentados como invasores de terras, desonestos, preguiçosos e privilegiados pelo governo.

Devido ao fato dos pequenos proprietários terem pouco ou nenhum conhecimento sobre os moradores do assentamento, oito de suas respostas se enquadram na categoria Não Sabem, o que mostra um distanciamento 
Tabela 4

Avaliação dos Assentados e de seus Vizinhos sobre o Contato Social Estabelecido com o Exogrupo

\begin{tabular}{lcc}
\hline \multirow{2}{*}{ Tipo de contato social com o exogrupo } & \multicolumn{2}{c}{ Freqüências } \\
& Assentamento & Comunidade vizinha \\
\hline Negativo/esteriótipos & 16 & - \\
Benéfico & 9 & 3 \\
Nenhum & - & 6 \\
Superficial & - & 5 \\
\hline
\end{tabular}

psicológico entre os grupos, uma vez que, fisicamente, existem todas as condições de distância para que eles possam ter contatos entre si.

Por fim, com o objetivo de conhecer outros aspectos da interação entre os grupos envolvidos no processo de assentamento, procurou-se conhecer como é o contato social estabelecido entre assentados e pequenos proprietários vizinhos ao assentamento (Tabela 4).

Entre os assentados, foram abordados dois aspectos: 1$)$ Contato negativo, devido ao fato dos pequenos agricultores atribuírem a eles adjetivos depreciativos, tais como violentos, ladrões de terra e baderneiros, com um total de 16 respostas; e 2) Contato benéfico, por afirmarem ter boa relação com seus vizinhos, com uma freqüência de nove respostas.

Diante do exposto, pode-se verificar que, em sua maioria, os assentados consideram que a relação com os pequenos proprietários não é positiva. Para os assentados, seus vizinhos não apresentam disposição para manter qualquer tipo de contato e ainda os chamam de ladrões de terra, vagabundos e baderneiros, sendo este o motivo principal pelo qual preferem manter distância. Estes aspectos confirmam a hipótese de que as percepções que um grupo tem de outro afetam negativamente o contato social.

A esse respeito, também se observou que os assentados manifestaram o interesse em manter isolamento em relação às comunidades circunvizinhas. Na visão dos assentados, uma vez que a falta de entendimento entre essas duas comunidades é marcante, quanto menor o contato, melhor deve ser para o assentamento. Por isso, os assentados pleitearam a implementação de postos de saúde, áreas de lazer e telefones públicos no assentamento, não só por causa da distância, mas, sobretudo, para não precisarem ter nenhuma aproximação com os moradores de fora do assentamento. Esta opinião foi expressa pela maioria dos assentados, exceto por aqueles que têm familiares morando nas comunidades circunvizinhas, o que mostra que os laços familiares constituem um forte ponto de apoio na pertença grupal.

Por outro lado, entre os agricultores vizinhos ao assentamento, foram abordados três aspectos em relação ao tipo de contato social mantido com o exogrupo: 1) Nenhum contato com os assentados, com seis respostas; 2) Superficial, quando existe contato entre os grupos, mas este contato se dá superficialmente, sem nenhuma intimidade, na feira, na igreja, ou em outro lugar, comparecendo com cinco respostas; e 3) Benéfico, quando os assentados e os pequenos agricultores vizinhos ao assentamento afirmam que mantêm contatos entre si, e os consideram como benéficos. Nas três respostas apresentadas, entretanto, não foram especificados que benefícios são estes.

De acordo com os resultados encontrados, torna-se possível verificar a existência de conflitos intergrupais, entre os assentados e seus vizinhos. Carvalho (1999) já havia contemplado este aspecto em seus estudos, quando constatou que entre os assentados e seus vizinhos havia uma certa desconfiança mútua e poucas afinidades. Os pequenos proprietários avaliam os assentados de forma negativa, pois os consideram como ladrões de terras e violentos. Por sua vez, os assentados consideram os pequenos proprietários como desorganizados e acomodados, indicando pouco ou nenhum aspecto positivo sobre a comunidade vizinha. A exceção fica por conta dos assentados que já tinham um certo grau de contato com os moradores de fora do assentamento. Isto se mostra de acordo com a afirmação de Sherif (1984) de que os conflitos não são gerados por intrigas pessoais, mas antes, constituem algo mais global, ocasionado pela limitação dos recursos, pela diferenciação entre as metas e pela existência da identidade grupal acentuada (ver, por exemplo, Bilig \& Tajfel, 1973; Turner, 1981).

Apesar da existência de conflitos e estereótipos de parte a parte, verifica-se que os pequenos proprietários avaliam positivamente a união e a coesão no assentamento, sendo também estes aspectos bem avaliados pelos próprios assentados. Pode-se concluir, então, que o que foi construído entre os membros do assentamento, também pode ser construído em relação aos seus vizinhos, mesmo que isto não seja fácil ou simples, sendo necessário um investimento psicológico para que os objetivos sejam alcançados. Nesta perspectiva, a psicologia social pode contribuir auxiliando a estruturação de novas relações entre estes grupos, fortalecendo sua aproximação e gerando um processo de integração entre eles. 


\section{Conclusão}

Neste estudo, partiu-se da premissa de que o assentamento poderá alcançar seu objetivo maior à medida que os assentados deixem de se diferenciar da comunidade que os cerca, passando a integrá-la e produzindo para a sua subsistência e comercialização. Pode-se verificar que este objetivo não tem sido alcançado, pois o preconceito e o conflito intergrupal estão muito presentes entre as comunidades envolvidas, quando o desejável seria justamente o contrário.

Apesar de parecer apenas psicológico, este problema é, acima de tudo, estrutural, haja vista a ausência de planejamento das políticas públicas voltadas para esta área, e de uma orientação unificadora das diversas comunidades envolvidas no processo de reforma agrária. Faz-se necessário trabalhar a micro-região como um todo, através da determinação de metas que, para serem alcançadas, necessitam do envolvimento e da cooperação, tanto dos assentados como dos seus vizinhos. Tal como foi verificado, realmente, o fato dos dois grupos estarem residindo numa mesma região não é condição determinante para que o envolvimento e a união aconteçam. É importante que sejam desenvolvidas atividades de trabalho, de lazer e de cultura, entre outras, que ajudem a diminuir a hostilidade e a manter a interdependência dos grupos aqui considerados. Através destas atividades, será possível o estabelecimento de normas e objetivos comuns, que contribuirão para relações menos conflituosas.

Outro aspecto importante é que, através dos recursos disponibilizados para o assentamento, sejam implantadas escolas, associações e postos de saúde, que possibilitem o maior contato social entre toda a comunidade, de forma que a região próxima ao assentamento seja também beneficiada. Tal benefício poderá ser auferido, não pela construção de prédios públicos, mas também pela concessão de créditos e assistência técnica para todos os agricultores, independentemente de serem ou não assentados.

A partir desta visão política, orientada para o desenvolvimento da agricultura familiar, de modo que trate os agricultores sem diferenciá-los devido a sua origem e/ou maneira de aquisição da terra, pode-se diminuir a existência de tais conflitos, integrando os assentados à comunidade circunvizinha. Cabe aos pesquisadores nas áreas das ciências sociais, e especificamente da psicologia, ajudar a entender este complexo problema e apontar, com indicadores técnicos, possíveis soluções que medeiem estas relações, de forma que os instrumentos de políticas públicas sejam cada vez mais aplicados em benefício do crescimento e do desenvolvimento da cidadania.

\section{Referências}

Albuquerque, F. J. B. (1994). Analisis del cooperativismo desde el punto de vista de la psicologia social. Tese de Doutorado não-publicada, Programa de Pós-graduação em Psicologia Social. Universidad Complutense de Madrid. Madrid, Espanha.

Albuquerque, F. J. B. (1996). Aspectos psicossociais do cooperativismo agrário. Em A. Tamayo, J. Borges-Andrade \& W. Codo (Orgs.), Trabalho, organizações e cultura (pp. 95-104). São Paulo: Cooperativa de Autores.

Albuquerque, F. J. B. (2000). Aspectos psicossociais da Agricultura Familiar nos Assentamentos e em seu entorno. Relatório: $\mathrm{CNPq} / \mathrm{UFPB}$.

Albuquerque, F. J. B. (2001). Aproximacíón metodologica desde la psicología social a la investigación en zonas rurales. Estudios Agrosociales y Pesqueros, 191, 255233.

Bar-Tal, (1996). Las Creencias Grupales como Expressión de la Identidade Social. Em J. F. Morales, D. Paez, J. C. Dechampes \& S. Worchel (Orgs.), Identidade Social: Aproximaciones psicosociales a los gruposy a las relaciones entre grupos (pp. 255285). Valencia: Promolibro.

Bilig, M. \& Tajfel, H. (1973). Social categorization and Similarity in intergroup behavior. European Journal of Social Psychology, 3, 29-52.

Bonavigo, E. A (1998). Produção Sócio-Histórica da "Cooperação Agrícola" no Acampamento da Fazenda Annoni e no Assentamento 16 de Marro": Práticas Cotidianas e Produções de Subjetividades. Dissertação de Mestrado não-publicada, Programa de Pós-graduação do Instituto de Psicologia da Universidade Federal do Rio de Janeiro. Rio de Janeiro, RJ.

Carvalho, H. M. (1998). Formas de associativismo vivenciadas pelos trabalhadores rurais nas áreas oficiais de Reforma Agrária no Brasil. Retirado em 05/04/2001, do World Wide Web: http://www.dataterra.org.br/documentos/horacio3.htm

Carvalho, H. M. De (1999). A interação social e as possibilidades de coesão e de identidade sociais no cotidiano da vida social dos trabalhadores rurais nas áreas oficiais de Reforma Agrária no Brasil. Retirado em 05/04/2001, do World Wide Web: http:// www.dataterra.org.br/documentos/horacio2.htm

Casal, C. H. (1989). Estructuray Procesos de Grupo. Madri, ES: Universidad Nacional de Educación a Distancia.

Clemente, M. \& Albuquerque, F. J. B. (1998). Aportes de la Psicologia Social al desarrollo rural: estudio sobre formación y desarrollo de las cooperativas agrarias. Em R. D. Vallejo \& J. D. V. Pastor (Org.), Psicología del trabajo. Nuevos conceptos, controversias y aplicaciones_(pp. 25-42). Madrid: Psicología Pirámide.

Clemente, M., Albuquerque, F. J. B. \& Reyes, T. (1993). Analisis del conflicto en el interior de las cooperativas agrarias y estrategias de superación. Madrid: Banco de Crédito Agrícola.

Drigotas, S. M., Insko, C. \& Schopler, J. (1996). Mera categoriazación y competición: Un examén más detallado de la teoria de la Identiade social y del efecto de discontinuidade. Em J. F. Morales, D. Paez, J. C. Dechampes \& S. Worchel (Orgs.), Identidade social: Aproximaciones psicosociales a los grupos y a las relaciones entre grupos (pp. 355-378). Valencia: Promolibro.

Jesuíno, J. C. (1996). Estructura e processos de grupos: Interações e factores de eficácia. Em J. Vala \& M. B. Monteiro (Orgs.), Psicologia Social (pp. 259-285). Lisboa: Fundação Calouste Gulbenkian.

Jorge, W. J. \& Bergamasco, S. M. P. P. (1998). O programa de crédito especial para reforma agrária brasileira - PROCERA - e a reprodução dos assentados: Um estudo no estado de São Paulo. Anais do XXXVIII Congresso Brasileiro de Economia e Sociologia Rural. http:// wnwn.cria.org.br/gip/gipaf/itens/pub/sober. Brasília, DF.

Krech, D., Crutchfield, R. S. \& Ballachie, E. L. (1962). Individual in society. New York: McGraw-Hill.

Krueger, R. A. (1996). Focus Groups: A practical guide for applied research. New York: Sage.

Lewin, K. (1948). Resolving social conflicts. New York: Harper and Row. Martinez, M. C. M. (1996). Analisis psicossocial del prejuicio. Madri, ES: Síntese. 
Montero, M. (1996). La Identidade social negativa: Un concepto en busca de la Teoria. Em J. F. Morales, D. Paez, J. C. Dechampes, \& S. Worchel (Orgs.), Identidade social: Aproximaciones psicosociales a los grupos y a las relaciones entre grupos (pp. 395-422). Valencia, ES: Promolibro.

Myers, D. (2000). Psicologia social. Rio de Janeiro, RJ: LTC.

Sherif, M. (1984). Conflito e cooperação. Em J. R. Torregrosa \& E. Crespo (Orgs.), Estúdios básicos de Psicología Social (pp. 585-605). Barcelona, ES: Centro de Investigações Sociológicas.

Turner, J. C. (1981). The experimental social psychology of intergroup behavior. Em J. C. Turner \& H. Giles (Orgs.), Intergroup Behavior (p. 78). Oxford, England: Blackwell.
Turner, J. C. (1994). El Campo de la Psicologia Social. Em F. Morales (Org.), Psicologia Social (pp. 17-28). Madri, ES: McGraw-Hill.

Sobre os autores

Francisco José Batista de Albuquerque é Psicólogo, Doutor e Pós-doutor pela Universidad Complutense de Madrid, Espanha. É Professor Adjunto da Universidade Federal da Paraíba.

Tatiana Cristina Vasconcelos é Psicóloga, Mestre em Psicologia Social pela Universidade Federal da Paraíba. É Professora do Centro de Ensino Superior São Francisco e bolsista na Universidade Federal da Paraíba.

Jorge Artur Peçanha de Miranda Coelho é Psicólogo. É Mestre em Psicologia Social pela Universidade Federal da Paraíba. 